\title{
Green brands and sustainable entrepreneurship
}

\author{
Tatiana Freze $^{1 *}$, Oksana Nurova ${ }^{1}$ \\ ${ }^{1}$ Institute of Engineering and Environmental Security, Togliatti State University, Belorusskaya str. 14, \\ 445020 Togliatti, Russian Federation
}

\begin{abstract}
Our paper focuses on the development of green brands as the part of the sustainable environmental management. It demonstrates that the main goal of the green technology is to focus on the specific interface of environmentally-friendly and sustainable technology, innovation and business development. It is building solutions that promote the development of clean energy, energy efficiency, renewable energy and efficient technologies. Moreover, it makes it clear that one should also underline the importance of sustainable transport, sustainable agriculture and sustainable urban development within this context. In addition, the paper focuses on the green marketing and environmental management as the parts of the sustainable entrepreneurship of the $21^{\text {st }}$ century. It becomes clear that environmental benefits of products and services should be highlighted and advertised by business companies in order to sustain their position on the globalized markets with severe competition.
\end{abstract}

\section{Introduction}

In the $21^{\text {st }}$ century, business companies need to refocus their business model to make the transition from the traditional to the sustainable future more efficient and sustainable [1]. This requires companies to challenge the traditional economic model and rebalance the economy away from consumption - towards growth and sustainable consumption. There is a growing movement in the business world towards sustainability as sustainability becomes increasingly important for buyers. Too often, "sustainable consumption" has been at the centre of discussion in business circles, but less so on the consumer side [2]. However, before we can make the transition as a whole society, we need to understand what sustainability is, what a sustainable business model is, what distinguishes it from the traditional economic model, and why this model is needed [3]. A key concept is to create and use "sustainable" business models through environmental and societal surplus, which means sustainability investments that have a secondary value through higher returns. We need a deeper understanding of the concept of sustainability and how itis relevant for the development of the company. Moreover, we need to understand what sustainability is, how it is compatible with the business world and the sustainability model in general. For example, agricultural banks provide farmers with preferential financing for the introduction of renewable agriculture and include net greenhouse gas sequestration in payment terms and compensation, thereby promoting farm sustainability and enabling the bank to accumulate

\footnotetext{
*Corresponding author: ntc@tltsu.ru
} 
new assets from available carbon offsets [4]. Grain producers are creating a sustainable business model to reduce emissions by using renewable energy sources such as wind, solar, biomass and biofuels.

Beyond the supply chain, companies are looking for new opportunities in the changing market for their products and services, including a shift to a more sustainable business model, such as the use of renewable energy sources. Consumers of these companies also offer behavioural skills as new assets for the business and pay a premium for them, as we have seen. Toyota Motor is seeking a wide range of partnerships to meet its goal of moving from zero environmental impact to eliminating $\mathrm{CO}_{2}$ emissions by 2050 [5]. Ford has developed the MyEnergi Lifestyle Program to explore ways to integrate the use of renewable energy sources such as wind and solar to reduce the overall carbon footprint. In addition to increasing the number of electric vehicles in its fleet, Ford also sees how customers would live a more electrified lifestyle overall [6].

In general, companies must now optimise the economic and social value in order to achieve overall, medium and long-term competitive returns for their shareholders. If properly defined, collective action can be empowering by limiting competitive movements in an industry and removing barriers that prevent companies from engaging in sustainability and a sustainable competitive advantage. In terms of returns on the stock market, the highsustainability companies have abnormal stocks - market performance is significantly higher than companies on a value-weighted basis, such as in the United States and Europe. These trends, which include a shift away from the traditional business model to the sustainability model, suggest that the public is no longer satisfied with corporations that focus exclusively on short-term profit maximization. Economic islands that maximise financial value and promotion independently are becoming obsolete [7]. Not surprisingly, more and more companies are exploring how environmental, social, and governance performance can contribute to financial performance.

Currently, there are only a few organisations that commit to sustainability on a broad basis as part of their business model. By contrast, the model of a company transforming the market is based on what we call market transformation. This means that companies respond to market changes by increasing their competitive position by integrating sustainability into existing business considerations. Business integration is geared to the present - today's measures of success, and the transformation of the market will help companies to create the measures of tomorrow. Instead of waiting for market changes to incentivize sustainable practices, companies can create these changes by enabling new forms of sustainability for companies.

\section{Green brands of the business companies}

Sometimes known as eco-marketing, green marketing is a way to highlight the environmental benefits of using a product or service. Many companies do green branding, which means they do everything in their power to reduce their carbon footprint and be greener. To achieve a green brand equity, a company must outline its environmental ethos, adopt sustainable production methods, offer sustainable products and services (e.g. renewable energy, energy efficient vehicles, etc.) and outline and highlight environmental issues [8]. When the world learns of the harmful effects of certain practices and products on the environment and the harmful effects of greenhouse gas emissions, the image of the "green brand" will show consumers that the company is caring and modern. When a friendly business company takes the lead, consumers can expect it to be perfect from day one. As if that were not enough, they also give $1 \%$ of their turnover to ecological organizations around the world that restore forests, dismantle dams, and protect endangered species [9]. One needs to talk to an environmental expert to know that one of the best things an environmentally 
friendly company can do is to overcome climate change. If business companies are honest with our customers and try to consistently improve our environmental practices, people would become devoted customers of the business.

Entrepreneurs who want to explore the green branding have to learn a lot from environmentally friendly companies. Green brands are those brands that connect consumers with environmental protection and sustainable business practices. When consumers become more aware of the need to protect the environment, such brands can appeal to a wide range of consumers, from small businesses to large corporations. Green brands can improve any company's image and give its products a unique selling point and awaken consumer interest in sustainability. However, this is only a sign of green marketing; in general, it is a much broader issue that can include consumer goods, technology and services in any country [10]. Unfortunately, most people believe that "green marketing" only applies to environmental issues such as climate change and energy efficiency. That is what most consumers associate with it, but in reality, it is much more. It also includes marketing activities that stimulate and confirm the attitude and environmental practices of customers, such as the use of environmentally friendly products and services and the promotion of environmental sustainability. Green marketing is typically practised by companies that are committed to sustainable development and corporate social responsibility. It is about companies promoting their products and services in a way that reflects their environmental friendliness. This strategy is known as green marketing and there are many types of marketing, whether in the form of advertising, public relations, social media, advertising campaigns or even advertising in newspapers [11]. The concept of green marketing seems to be due to the negative impact of humans on the planet. Products and services can be sold by highlighting their environmental benefits and consumers recognise such brands. This is called eco-marketing or environmental marketing and is one of the most popular marketing strategies in the world. The eco-friendly trend has been so massive in recent years that it has spawned a number of companies, including Coca-Cola, PepsiCo, McDonald's, Nestlé and many others. Green marketing is a way for companies to sell their products and services in a way that emphasizes their sustainability efforts and environmental benefits [12]. If done right, brands that implement green marketing in their culture, strategy, and target audience, increase sales and profits, can help save the planet and appeal to their target audiences. Some companies are using this strategy to highlight how their mission is to help the environment, rather than just increase revenue.

\section{Environmental management for sustainable entrepreneurship}

Sustainable entrepreneurship builds on the foundations of entrepreneurship and extends it to integrate environmental and social concerns within existing companies. Sustainable economy recognizes the growing scientific evidence and growing evidence that growing social inequalities are destroying the economy, the environment and global society [13]. It recognises these changes by recognising that the consumer public is increasingly concerned about the challenges of a sustainable world. This market opportunity involves addressing sustainability concerns by providing new products and services that reduce energy and resource consumption.

Green supply chain practices can be used to improve the quality, efficiency, sustainability and cost-effectiveness of the SME production process in a given country. Sporting goods manufacturer Puma is an example of a company that successfully invests in sustainable business practices and adopts green supply chain practices that measures the environmental footprint of the company's business, including the way these raw materials are extracted [14]. It is used as a tool to raise awareness of the importance of the environment and sustainability in the economy. A senior management survey showed that sustainable development is 
becoming the focus of business models against the trend. According to some studies, more than a half of the companies already have a specific strategy for the environment [15]. Automotive industry can be used as an example of how a very traditional industry is facing up to the challenges of sustainability and looking to the future, which highlights the importance of sustainability in its business model [16]. The economic source must be tapped from an organizational structure based on a culture and philosophy that transforms organizational structures and manages to induce companies to promote the development of any country. As such, it is intended to support sustainable entrepreneurs in using business models to unlock the potential of their business model, for example to improve the environmental and social values created. This framework is based on theoretically sound assumptions, such as the ability to mediate between the need to solve an environmental or social problem with valuable results.

Concepts of sustainability and corporate responsibility connect stakeholders, including governments, suppliers, customers, communities and others. At the same time, it increases the need for improvements in the company's internal processes, including the integration of environmental and social responsibility into the business process and the development of a sustainable business model [17]. The fundamental motivation for this approach is that the creation of links between stakeholders in the value chain opens up new opportunities for the development of a sustainable business model and the creation of new business models. A more difficult task is to assess what we believe is necessary for sustainable entrepreneurship to succeed. Therefore, work continues to develop tools to implement and track sustainability initiatives, track and measure their performance, and integrate sustainability into strategic business processes [18]. Further instruments for sustainable entrepreneurship are the development of sustainable business models and business-to-business (B2B) relations. These are in place, but are often criticized for being difficult to implement in the context of a business model with a high degree of uncertainty and uncertainty about its long-term viability. There is business-oriented perspective that focuses on the development of sustainable business models and business-to-business (B2B) relationships. How do product design, processes and supply chains have environmental consequences that can improve or impair a company's economic performance? How do managers create value by making sustainable business models and business relationships (B2B) more sustainable? How do they analyse product and process performance over the course of a lifetime-circular thinking? How to assess different types of sustainability initiatives and their impact on business and the environment? All of these are not easy questions.

This is why managers and managers are called upon to improve their organisational skills in order to cope with the emerging challenges facing the internal and external environment of companies. Furthermore, feed duties have been found to have had a positive impact on the supply chain of food and beverage companies in the United States and other countries. Companies are being asked to increasingly practice eco-innovation in their supply chains, operations and operations.

\section{Green brands and marketing instruments}

There are many competitive green brands that managed to offer environmentally friendly products that provide a solid environmental performance. Environmental concerns are combined with a marketing strategy known as green marketing, in which the company makes a number of commitments to meet environmental concerns, such as revised advertising and changing production processes [19]. Green brands can be profitable in the market, where they can charge an exclusive price for a product that conscious consumers are willing to pay. Green Brands create thus add another value, which is conveyed by their communication strategy. Green marketing is a way for companies to sell their products and services in a way 
that emphasizes their sustainability efforts and environmental benefits. The eco-friendly trend has been so massive in recent years that it has spawned a number of different types of green marketing strategies, such as eco-friendly advertising and green branding. These strategies are used by companies to underscore how their mission is to help the environment, rather than just increase revenue. If done right, brands that introduce green marketing into their culture and strategy can reach their target audience, increase the company's revenue and profits, and help save the planet [20].

Consumers, shareholders and society as a whole benefit when companies integrate environmental friendliness into their marketing strategies. Branding a green company can create a more positive public image, which in turn can boost sales and drive-up share prices. A green image can also lead to consumers having an increased affinity for the company's specific products, which increases brand loyalty. If implemented correctly, green marketing can help to increase the emotional connection between consumers and brands. It can also be informative and precise to increase consumer awareness, thereby improving overall environmental quality and the sale of green alternatives. Eco-labelling is intended to facilitate the creation of a consumer-friendly environment in which consumers who value product characteristics and environmental qualities in particular can express this preference. This helps to confuse consumers on sustainability indicators [21]. Businesses must not only increase sales of green products, but also ensure that consumers understand the return on their investments in finance and the environment. Consumers need to know and trust the label so that they can make purchasing decisions. By presenting this information in a simple and clear way, consumers can choose energy-efficient products and save money. If consumers find it easy to track their savings from using these products, they are less likely to try more expensive or more expensive products. They are more likely to trust in environmentally friendly purchases if they understand how the product helps the environment. Together with the global burden on the planet and the environment, which requires environmentally friendly products and healthy living, we are creating global pressure for more energy - efficient, sustainable and sustainable products [22].

Many products have green offerings and many companies participate in eco-friendly practices while they use marketing companies and brands that represent "green" to make the most of their brand and marketing efforts. This includes things like green products, services and even your own logo and logo design. There are many types of marketing for this, but this strategy is known as green marketing, and it is called eco-marketing or environmental marketing. By highlighting the environmental benefits of products and services, companies can sell them in a way that consumers recognise such brands as being more environmentally friendly than their competitors [23]. The concept of green marketing is derived from the impact of the negative impact of man on the planet. Green marketing refers to the development of products based on their perceived environmental sustainability, not their actual environmental impact. Examples of "green marketing" are advertising the reduced emissions associated with the manufacturing process of a product and the environmental benefits of the product. One can choose how the product is made from recycled materials or how it is recycled or reused, but one must make sure that you practice what she or he preaches. If a company's business practices do not match its green marketing message, they risk being labelled dishonest.

\section{Conclusions}

Overall, sustainable and green entrepreneurship focuses on people, industries and disciplines with an emphasis on green technology, innovation, business and business development. This is a clean-tech accelerator that encourages innovation to create a healthier environment and a more prosperous future. Green technologies are on the rise, and there are 
amazing green innovations around the world that are helping us to live more sustainably. From old milk clothes to energy-efficient cars, this guide reveals our five favourite green technology projects. More and more innovators and organizations are driving green technologies forward and visualizing and promoting sustainable innovations. A new age of innovators is exploring areas that no one has ever ventured into, from energy-efficient cars to smart homes and smart cities. In this sense, there is a long list of green technologies involved in sustainable innovation and their impact on the environment and the economy.

All of these makes a major step forward in terms of environmental sustainability, as it can reduce both the size and cost of plastics and reduce both the quantity and the amount of plastic landfills and oceans. It is now becoming apparent that our planet is beginning to choke on the pollution we are causing, and this should lead to a significant reduction in the amount of plastic waste in our oceans and landfills, as well as in rivers and streams. This will not only save resources, but also significantly reduce the annual waste and promote green brands and sustainable entrepreneurship.

\section{References}

1. B.S. Silvestre, D.M. Ţîrcă, Journal of Cleaner Production, 208, 325-332 (2019)

2. E. Lisin, D. Shuvalova, I. Volkova, W. Strielkowski, Sustainability, 10(4), 1111 (2018)

3. F. Hofmann, M. Jaeger-Erben, Business Strategy and the Environment, 29(6), 2770$2788(2020)$

4. G. Beck, Dictionary of $21^{\text {st }}$ Century Energy Technologies, Financing and Sustainability (2021)

5. Toyota, https://global.toyota/pages/global_toyota/sustainability/report/er/er20_en.pdf (2020)

6. Ford, https://media.ford.com/content/fordmedia/fna/us/en/news/2014/01/08/charge-upyour-home--ford-motor-companys-myenergi-lifestyle-2-0-.html (2014)

7. P. Haessler, Administrative Sciences, 10(3), 63 (2020)

8. H. Zameer, Y. Wang, H Yasmeen, Journal of cleaner production, 247, 119119 (2020)

9. S. Kolosok, T. Pimonenko, A. Yevdokymova, N. Hajiyev, M. Palienko, L. Prasol, Marketing and Management of Innovations, 4, 50-60 (2020)

10. T.K. Panda, A. Kumar, S. Jakhar, S. Luthra, J.A. Garza-Reyes, I. Kazancoglu, S.S. Nayak, Journal of Cleaner production, 243, 118575 (2020)

11. R. Rameshwar, R. Saha, S.N. Sanyal, Corporate Social Responsibility and Environmental Management, 27(6), 2816-2830 (2020)

12. W. Visser, CSR 2.0: Transforming corporate sustainability and responsibility (2014)

13. F. Lüdeke-Freund, Business Strategy and the Environment, 29(2), 665-681 (2020)

14. S. Gröschl, P. Gabaldón, T. Hahn, Journal of Business Ethics, 155(3), 741-762 (2019)

15. L. Ardito, R.M. Dangelico, Corporate Social Responsibility and Environmental Management, 25(4), 426-440 (2018)

16. V. Parida, D. Sjödin, W. Reim, Sustainability, 11, 391 (2019)

17. M.A. Camilleri, Asian Journal of Sustainability and Social Responsibility, 2(1), 59-74 (2017)

18. M. Kravchenko, D.C. Pigosso, T.C. McAloone, Journal of Cleaner Production, 241, 118318 (2019)

19. M.L. Tseng, M.S. Islam, N. Karia, F.A. Fauzi, S. Afrin, Resources, Conservation and Recycling, 141, 145-162 (2019)

20. P. Nistoreanu, A.C. Aluculesei, D. Avram, The Romanian Experience. Information, 11(8), 389 (2020)

21. I. Gåvertsson, L. Milios, C. Dalhammar, Journal of Consumer Policy, 43(2), 1-25 (2020) 
22. P. Senge, B. Smith, N. Kruschwitz, J. Laur, S. Schley, The necessary revolution: How individuals and organizations are working together to create a sustainable world (2008)

23. K. White, D.J. Hardisty, R. Habib, Harvard Business Review, 11, 124-133 (2019) 